\title{
AN INTEGRATED COMPUTER BASED TECHNICAL PROCESSING SYSTEM IN A SMALL COLLEGE LIBRARY
}

Jack W. SCOTT: Kent State University Library, Kent, Ohio (Formerly Lorain County Community College, Lorain, Ohio)

A functioning technical processing system in a two-year community college library utilizes a model 2201 Friden Flexowriter with punch card control and tab card reading units, an IBM 026 Key Punch, and an IBM 1440 computer, with two tape and two disc drives, to produce all acquisitions and catalog files based primarily on a single typing at the time of initiating an order. Records generated by the initial order, with slight updating of information, are used to produce, via computer, manual and mechanized order files and shelf lists, catalogs in both the traditional $3 x 5$ card form and book form, mechanized claiming of unfilled orders, and subject bibliographies.

The Lorain County Community College, a two-year institution designed for 4000 students, opened in September 1964, with no librarian and no library collection. When the Librarian was hired in October 1964, lack of personnel, both professional and clerical, forced him to examine closely traditional ways of ordering and preparing materials, his main task being the controlled building of a collection as quickly as possible.

No library having been established, there were no inflexible rules governing acquisitions or cataloging and no catalogs or other files enforcing their pattern on future plans. The Librarian was free to experiment and adapt as much as he desired; and adapt and experiment he did, remembering, at least most of the time, the primary reasons for designing the 
system. These were 1) to notify the vendor about what material was desired; 2) to have readily available information about when material had been ordered and when it might arrive; 3 ) to provide a record of encumbrances; 4) to make sure that material received was the material which had been ordered; 5) to initiate payment for material received; 6) to provide catalog copy for technical processes to use in producing card and book catalogs; 7) to provide inexpensive control cards for a circulation system; and 8) to provide whatever other statistics might be needed by the Librarian.

The Librarian attended the Purdue conference on library automation (October 2-3, 1964) and an IBM conference on automation held in Cleveland (December 1964), and visited libraries with data processing installations, such as the Decatur Public Library. Then an extensive literature search was run on the subject of mechanization of libraries and the available material thoroughly reviewed. It was the consensus of the President, the Librarian, and the Manager of Data Processing that, as White said later, "The computer will play a major part in how libraries are organized and operated because libraries are a part of the fabric of society and computers are becoming a daily accepted part of life." (1) Moreover, it was agreed that the use of data processing equipment would be justified only if it made building a collection more efficient and more economical than manual methods could do.

\section{METHOD}

After careful consideration of the IBM 870 Document Writing System (2) and the system described by Kraft (3) as input techniques for the College Library, it was decided to use the Friden Flexowriter, recommended both at Purdue and, in European applications, by Bernstein (4). Its most attractive feature was the use of paper tapes to generate various secondary records without the necessity of proofreading each one.

The College, by mid-1965, had the following equipment available for library use: one Friden Flexowriter (Model 2201) with Card Punch Control Unit and Tab Card Reading Unit, one IBM 026 Key Punch with alternate programming, and guaranteed time on the college-owned IBM $14408 \mathrm{~K}$ computer with two tape and two disc drives. To produce punched paper tape and tab cards with only one keyboarding, an electrical connection between the Flexowriter and the keypunch was especially designed and installed.

It was fortunate for the Library that the College also had an excellent Data Processing Manager who was interested in seeing data processing machines and techniques utilized in as many ways as possible. With his enthusiastic support, aid in programming and preparation of flow charts, and patient cooperation, it was not surprising that the automation of library processes was completely successful.

At this time it was decided that since the college was likely to remain 
a single-campus institution it would be uneconomical to rely solely on a book catalog, even though the portability of such a device was most attractive to Librarian and faculty alike. Therefore, it was planned to have the public catalog, as well as the official shelf list, in card form, permitting both to be kept current economically. These two files were to be supplemented with crude book catalogs which would be a by-product, among others, of the typing of the original book orders. These book catalogs were not to replace the card catalog but simply to extend and facilitate use of the collection.

It was also decided to design a system which would duplicate as few as possible of the manual aspects of normal technical processing systems, but one which would, at the same time, permit the return to a manual system from a machine system with a minimum of trouble and tribulation if support for the Library's automated system should be withdrawn. Concern about such withdrawal of support had originally been voiced by Durkin and White in 1961, when they said: "There have been a number of unfortunate examples of libraries that abandoned their home-grown catalogs for a machine retrieval program because there was some free computer time, only to lose their machine time to a higher priority project and to be left with information storage to which they no longer have access. Many of these librarians, and others who have heard about their plight, are determined not to burn their bridges behind them by abandoning their reliable, if old-fashioned, $3 \times 5$ card catalogs." (5)

Although the necessity of returning to an inefficient manual system has not, to date, raised its ugly head, there were times when it was most comforting to know that routes of retreat and reformation were available.

Under the present system there is only one manual keyboarding of descriptive catalog main entries for most titles. All other records are generated from these main entries. This integrated system was adopted on the assumption that cataloging information in some form (6) would be available for a high percentage of books. Experience showed that about 95 percent of acquisitions did have catalog copy readily available. Of 4029 titles processed in a 5-month period, catalog copy was available for 3824 .

After verification that a requested title is neither in the library nor on order, a copy of a catalog entry is located in a source such as the National Union Catalog, Library of Congress proofsheets, or Publisher's Weekly, etc. The catalog information is manually typed in its entirety (including subject headings) onto five-part multiple request forms, using the Friden Flexowriter. Output from the Friden consists of the multiple order, a punched paper tape containing the full bibliographic entry but no order information, and tab cards, punched by the slave IBM Key Punch, which contain full order information but only abbreviated bibliographic data. (Figure 1). The tab cards, containing full order information, are used as input to the 1440 computer to create an "on order" file arranged by order 
152 Journal of Library Automation Vol. 1/3 September, 1968

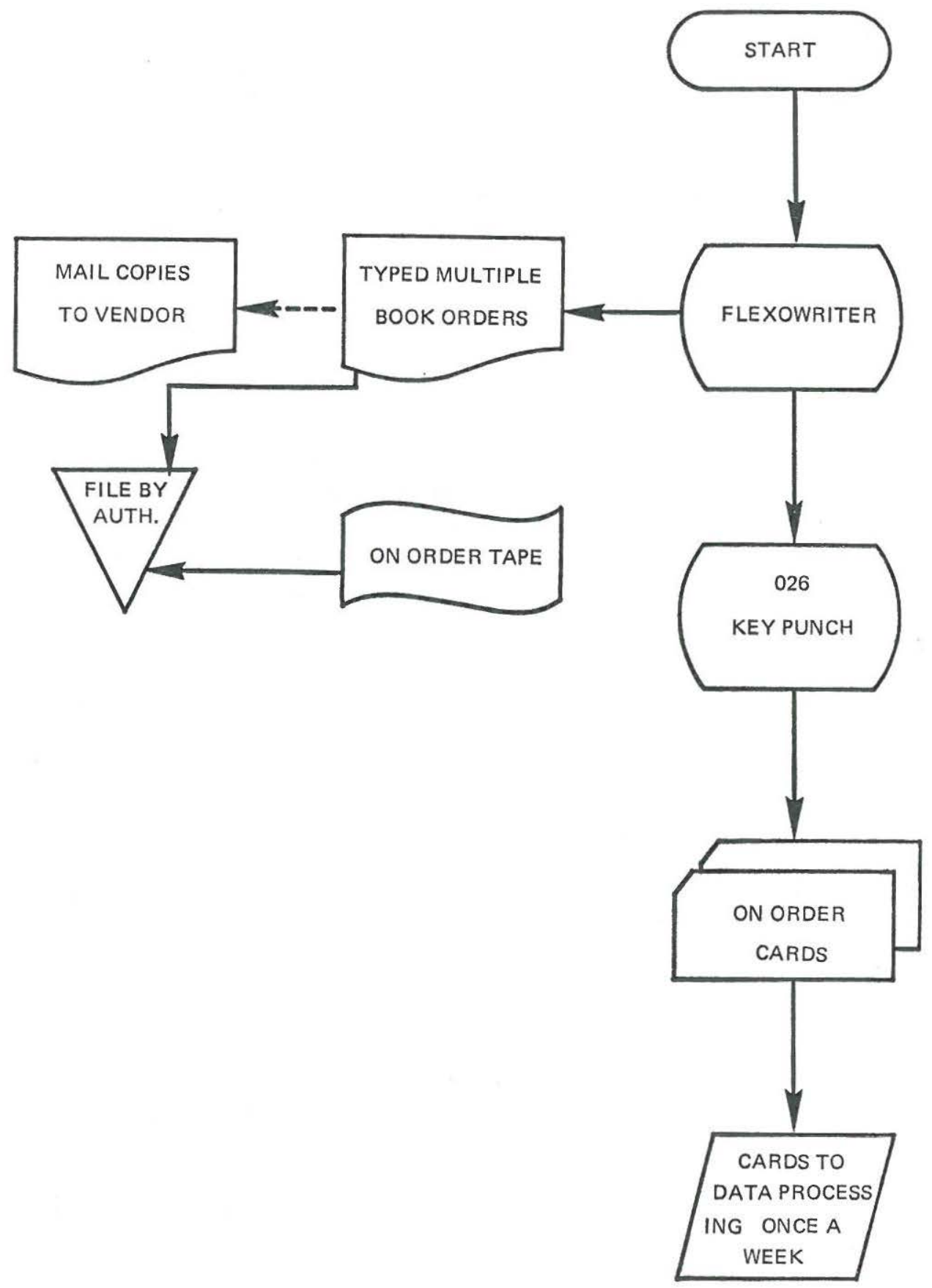

Fig. 1 On Order Creation Routine. 
number and stored on magnetic tape, from which an "on order" printout is produced weekly (Figure 2). At any given time this magnetic tape order file can be used to total the dollar amount of outstanding orders to any given vendor, or the total amount outstanding to all vendors (Figure 3).

The punched paper tape and two copies of the Request Form are stored in a standard $3 \times 5$ card file arranged by main entry. One copy of the Request Form is to be used as a work slip when material is received.

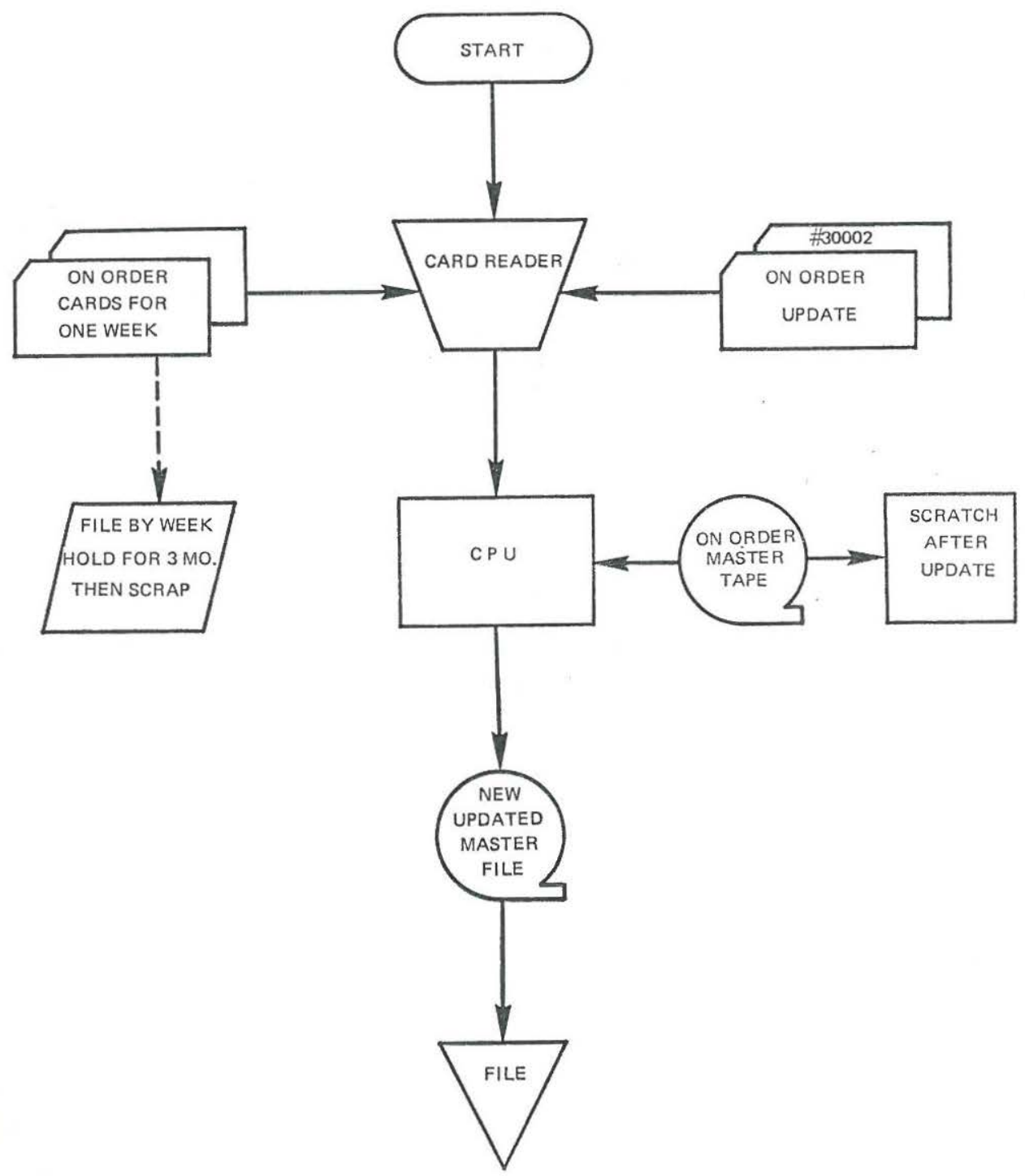

Fig. 2 On Order Update. 
The original and one copy of the Request Form is sent to the vendor, with instructions to return one copy with shipment. In the event the vendor does not comply, the main entry can be located readily by checking the order number or order date on the "on order" printout and using the abbreviated bibliographic information which appears there.

If the material requested has not been shipped within three months, the magnetic tape order file is used to prepare tab cards containing all original order information and the cards are sent to the Library with a notice stating that shipment is overdue. These tab cards are used as input

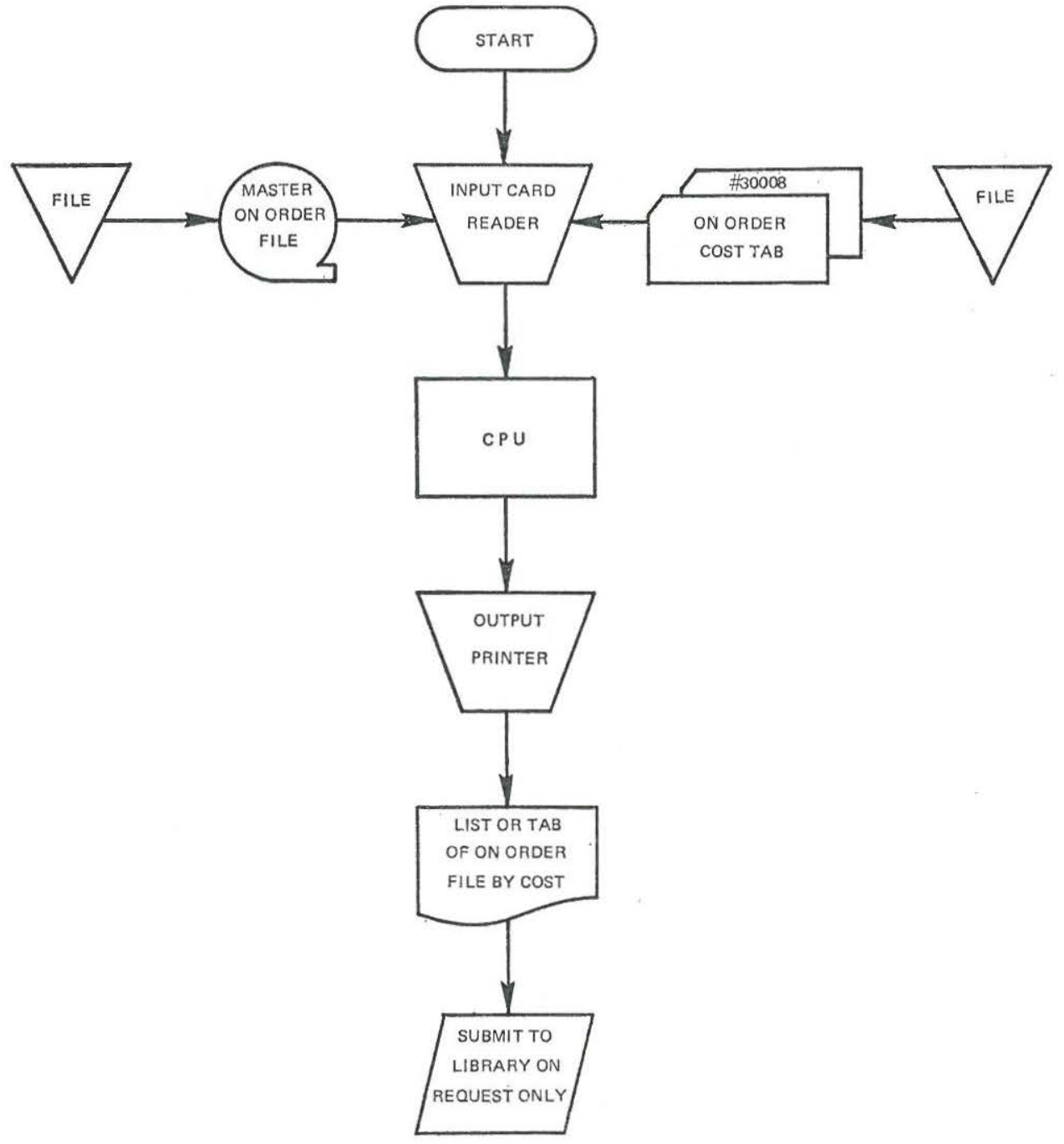

Fig. 3 On Order Cost Tally. 
to the Flexowriter tab card reader unit which activates the Flexowriter itself and prepares "overdue, ship or cancel" notices to the vendor (FigFig. 4 Late On Order Routine.

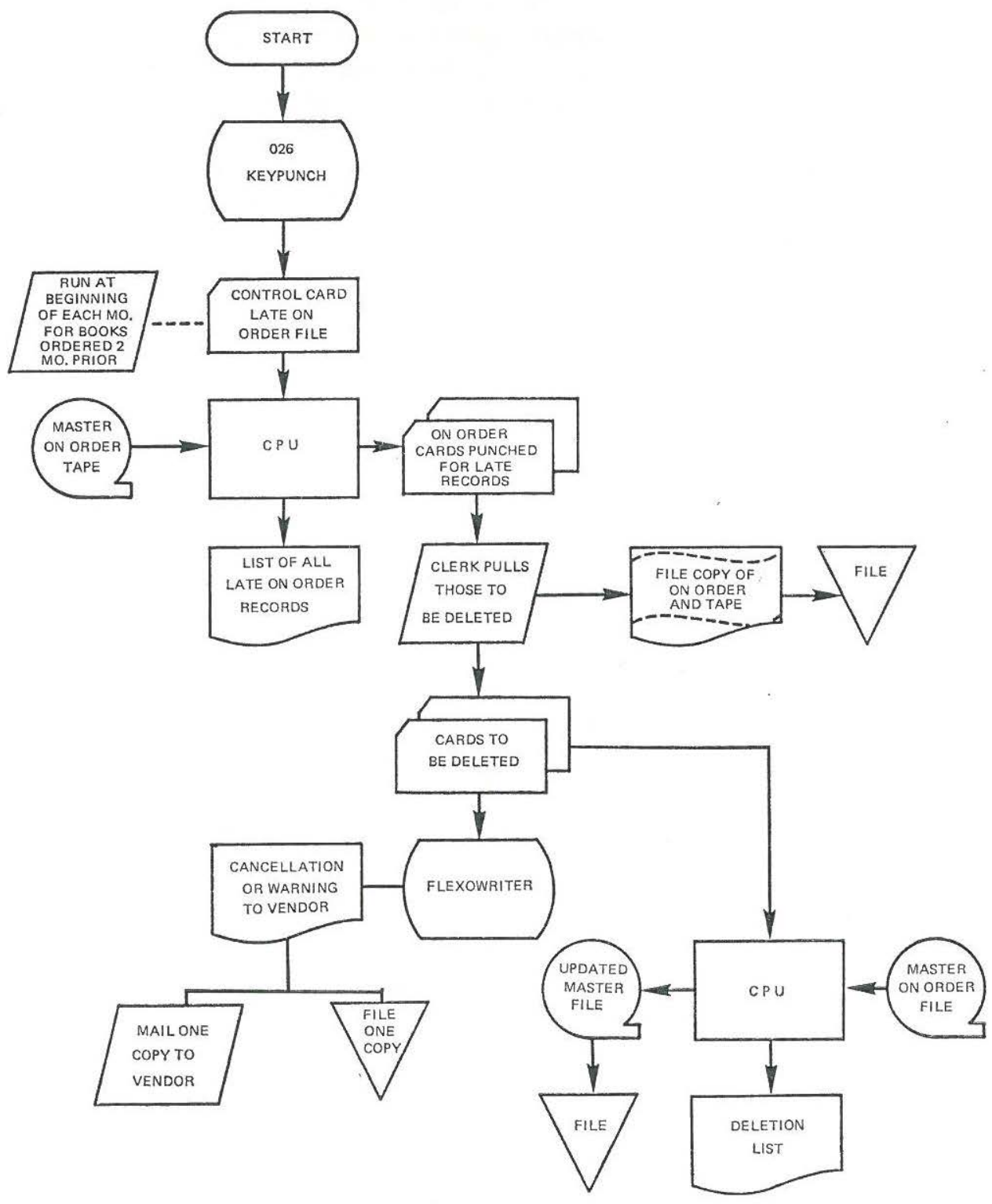

ure 4). 


\section{PRODUCTS}

When material is received, the paper tape and one copy of the main entry work slip are pulled from the card order file and sent to the cataloger who notes on the work slip the call number to be used as well as any changes. The work slip, punched paper tape and book then pass to the technician who does the shelf listing.

At this point the original output paper tape containing full bibliographic information is used as input for the Flexowriter to create a standard $3 \times 5$ hard-copy shelf list card containing full bibliographic information, as well as inventory data such as vendor, date of receipt and cost. The last three items and the call number are added manually as "changes." Simultaneously a new paper tape is produced as output which contains bibliographic information from the first tape and all revisions deemed necessary by the cataloger. The revised paper tape is used on the Flexowriter to prepare $3 \times 5$ card sets for the public catalog. At the same time the slave keypunch prepares a set of tab cards containing full acquisitions

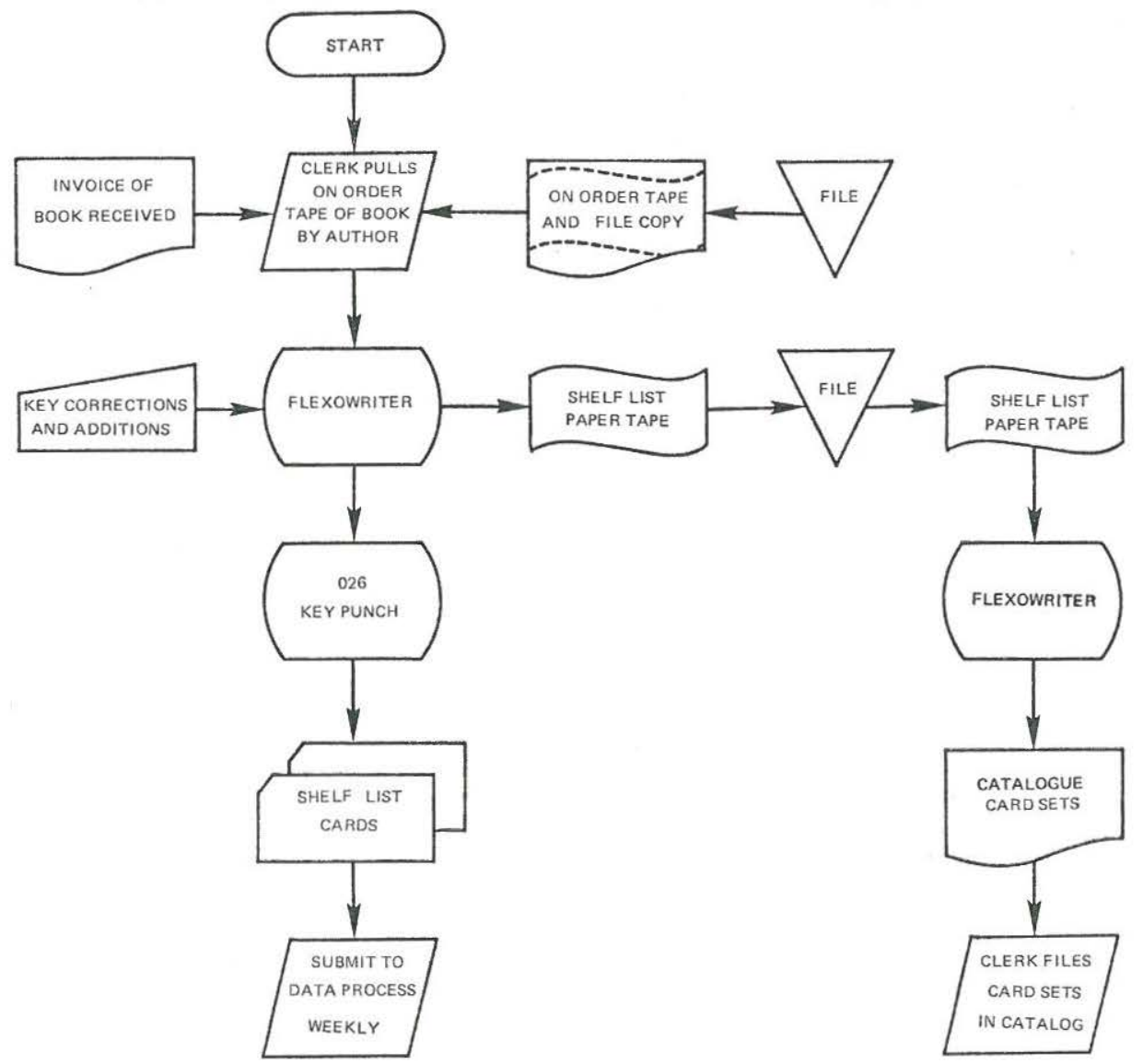

Fig. 5 Shelf List Creation Routine. 
information: cost, vendor, date of receipt; and abbreviated bibliographic information: short author, short title, full call number (including copy, year, part and volume), accession number and short edition statement (Figure 5). The tab cards are used first to delete the item from the magnetic tape "on order" file and second as input to create a magnetic tape shelf list of abbreviated information arranged by call number (Figure 6). The magnetic tape shelf list is used to create 1) eight copies of author, title, and classified catalogs which are updated semi-annually; 2) printouts of weekly acquisitions; 3) subject printouts on demand; and 4) tab cards which serve as circulation cards for books, films, drawings, tape and disc recordings, filmstrips and any other materials. The tab cards can be used with the IBM 357 circulation system or any similar system.

\section{DISCUSSION}

The efficiency of this system is most dramatically demonstrated by the amount of work accomplished per person per year. One technician can

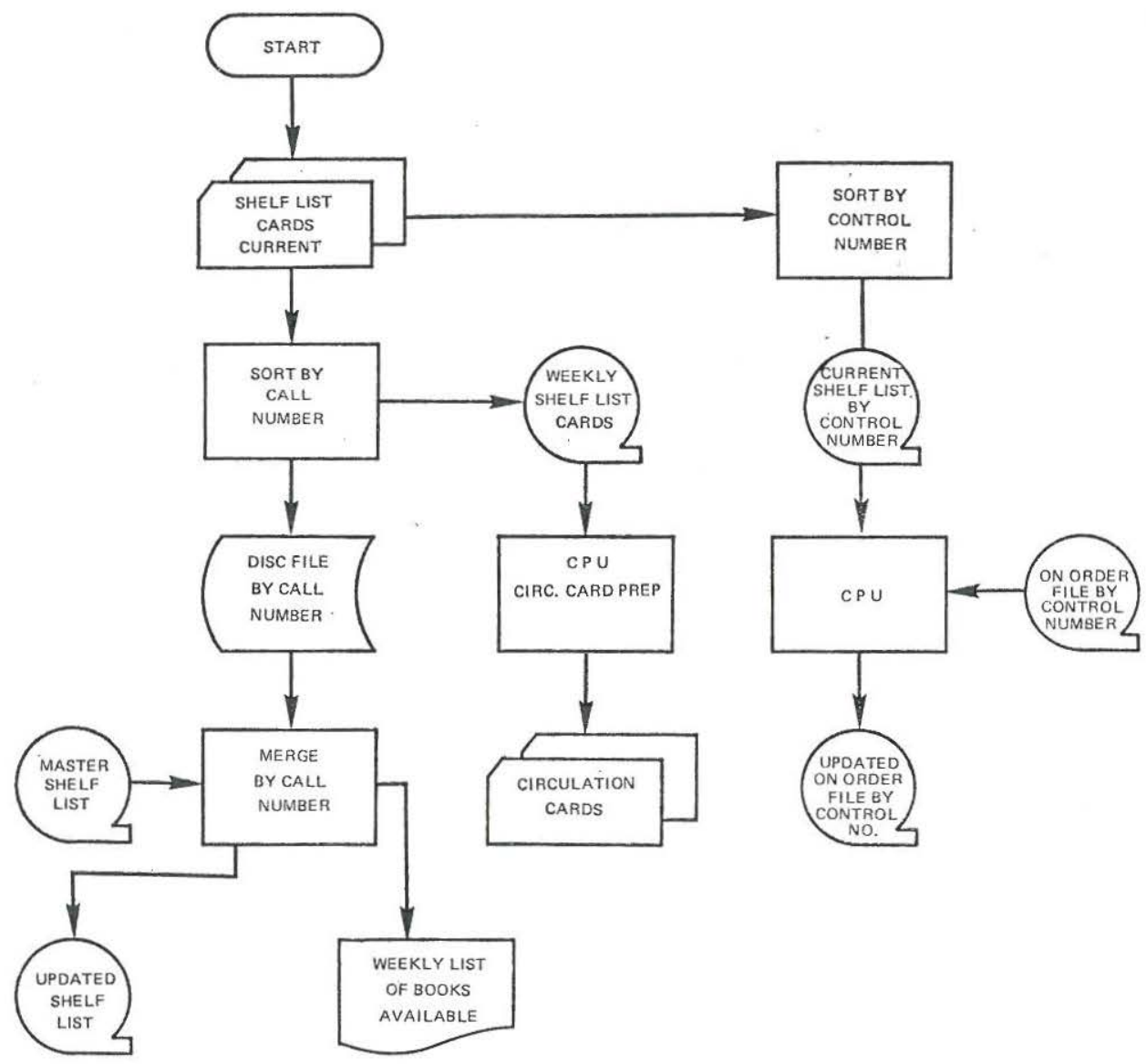

Fig. 6 Weekly Shelf List Update. 
process over one thousand orders per month. Over fifteen thousand fully cataloged volumes per year (approximately eleven thousand titles) are added to the collection by a technical processing department which consists solely of one full-time cataloger and two full-time technicians. One technician spends one half of her time typing orders and the other half preparing the shelf list. At present the limiting factor in processing material is not the personnel time available but rather time on the Flexowriterkeypunch combination, which runs continuously for sixty hours per week. The cataloger feels if some thirty hours more per week were available for running the machines, or if a second Flexowriter were available to handle catalog card output, it would then be possible to order, receive, and fully process fifteen thousand titles per year (eighteen to twenty thousand volumes) with only the present technical processing staff.

\section{REFERENCES}

1. White, Herbert S.: "To the Barricades! The Computers are Coming!" Special Libraries 57 (November, 1966), 631.

2. General Information Manual: Mechanized Library Procedures (White Plains, N.Y.: IBM, n.d.).

3. Kraft, Donald H.: Library Automation with Data Processing Equipment (Chicago: IBM, 1964).

4. Bernstein, Hans H.: "Die Verwendung von Flexowritern in Dokumentation und Bibliothek", Nachrichten fur Dokumentation 12 (June, 1961), 92.

5. Durkin, Robert E.; White, Herbert S.: "Simultaneous Preparation of Library Catalogs for Manual and Machine Applications", Special Libraries 52 (May, 1961), 231.

6. Kaiser, Walter H.: "New Face and Place for the Catalog Card", Library Journal 88 (January, 1963), 186. 